\title{
A Note on Domatic Subdivision Stable Graphs
}

\author{
M. Yamuna*, K. Karthika \\ School of Advanced Sciences, VIT University, Vellore, Tamilnadu, India \\ *Corresponding Author: myamuna@vit.ac.in
}

Copyright $@ 2014$ Horizon Research Publishing All rights reserved.

\begin{abstract}
A domatic partition of a graph $\mathrm{G}=(\mathrm{V}, \mathrm{E})$ is a partition of $\mathrm{V}$ into disjoint sets $\mathrm{V}_{1}, \mathrm{~V}_{2}, \ldots, \mathrm{V}_{\mathrm{K}}$ such that each $V_{i}$ is a dominating set for $G$. A subdivision of a graph $G$ is a graph resulting from the subdivision of edges in $G$. In this paper we discuss about the minimal properties of domatic subdivision stable graph and we show that every graph is an induced subgraph of a domatic subdivision stable graph. We discuss methods of generating new domatic subdivision stable graphs from existing domatic subdivision stable graphs using graph operations.
\end{abstract}

Keywords Domatic Partition, Subdivision, Dominating Set, Minimal Set

\section{Introduction}

We consider only simple connected undirected graphs $\mathrm{G}=$ $(\mathrm{V}, \mathrm{E}) . \mathrm{P}_{\mathrm{n}}$ denotes the path of length $\mathrm{n}$. The open neighborhood of vertex $\mathrm{v} \in \mathrm{V}(\mathrm{G})$ is defined by $\mathrm{N}(\mathrm{v})=\{\mathrm{u}$ $\in \mathrm{V}(\mathrm{G}) \mid \mathrm{u} v \in \mathrm{E}(\mathrm{G})\}$ while its closed neighborhood is the set $\mathrm{N}[\mathrm{v}]=\mathrm{N}(\mathrm{v}) \cup\{\mathrm{v}\}$. The private neighborhood of $\mathrm{v} \in$ $\mathrm{D}$ is defined by pn $[\mathrm{v}, \mathrm{D}]=\mathrm{N}(\mathrm{v})-\mathrm{N}(\mathrm{D}-\{\mathrm{v}\})$. We say that $H$ is a subgraph of $G$, if $V(H) \subseteq V(G)$ and $u v \in E(H)$ implies $u v \in E$ ( $G$ ). If a subgraph $H$ satisfies the added property that for every pair $u, v$ of vertices, $u v \in E(H)$ if and only if $u v \in E(G)$, then $H$ is called an induced subgraph of $\mathrm{G}$ and is denoted by $<\mathrm{H}>$. We indicate that $\mathrm{u}$ is adjacent to $\mathrm{v}$ by writing $\mathrm{u} \perp \mathrm{v}$. For properties related to graph theory we refer to West, D. B, [1].

A set of vertices $D$ in a graph $G=(V, E)$ is a dominating set if every vertex of $\mathrm{V}-\mathrm{D}$ is adjacent to some vertex of $\mathrm{D}$. If $\mathrm{D}$ has the smallest possible cardinality of any dominating set of $G$, then $D$ is called a minimum dominating set abbreviated MDS. The cardinality of any MDS for $G$ is called the domination number of $\mathrm{G}$ and it is denoted by $\gamma$ ( $G$ ). A $\gamma$ - set denotes a dominating set for $G$ with minimum cardinality. A dominating set $\mathrm{D}$ is minimal dominating if no proper subset of $\mathrm{D}$ is a dominating set. A vertex in $\mathrm{V}-\mathrm{D}$ is $\mathrm{k}$ - dominated if it is dominated by at least $\mathrm{k}$ - vertices in D. For properties related to domination we refer to Haynes, T. W. et al., [3, 4].

In [2], Vestergaard, P. D. et al., have studied the domatic numbers and total domatic numbers of graphs having cut vertices. In Theorem 1, 3 and 4 of [2], they have provided upper bounds related to domination numbers and provided conditions for attaining the sharp bounds.

In [6], Yamuna, M. et al., have defined domatic subdivision stable graphs. In Theorem 1, 2 and 3 of [6], they have provided bounds for domatic subdivision stable graphs and obtained necessary and sufficient conditions for the domatic partition of the domatic subdivision stable graphs.

\section{Materials and Methods}

A domatic partition of a graph $\mathrm{G}=(\mathrm{V}, \mathrm{E})$ is a partition of $\mathrm{V}$ into disjoint sets $\mathrm{V}_{1}, \mathrm{~V}_{2}, \ldots, \mathrm{V}_{\mathrm{K}}$ such that each $\mathrm{V}_{\mathrm{i}}$ is a dominating set for $\mathrm{G}$. The domatic number is the maximum number of such disjoint sets and it is denoted by $\mathrm{d}(\mathrm{G})$.

A subdivision of a graph $\mathrm{G}$ is a graph resulting from the subdivision of edges in $\mathrm{G}$. The subdivision of some edge e with endpoints $\{\mathrm{u}, \mathrm{v}\}$ yields a graph containing one new vertex w, and with an edge set replacing e by two new edges, uw and wv. We shall denote the graph obtained by subdividing any edge uv of a graph $\mathrm{G}$, by $\mathrm{G}_{\mathrm{sd}} \mathrm{uv}$. Let $\mathrm{w}$ be a vertex introduced by subdividing uv. We shall denote this by $\mathrm{G}_{\mathrm{sd}} \mathrm{uv}=\mathrm{w}$.

Yamuna, M and Karthika, K. [6], defined a new graph called domatic subdivision stable graph. A graph $\mathrm{G}$ is said to be domatic subdivision stable( dss ), if $d(G)=d\left(G_{s d} u v\right)$, for all $u v \in E(G)$.

Example of Dss Graph
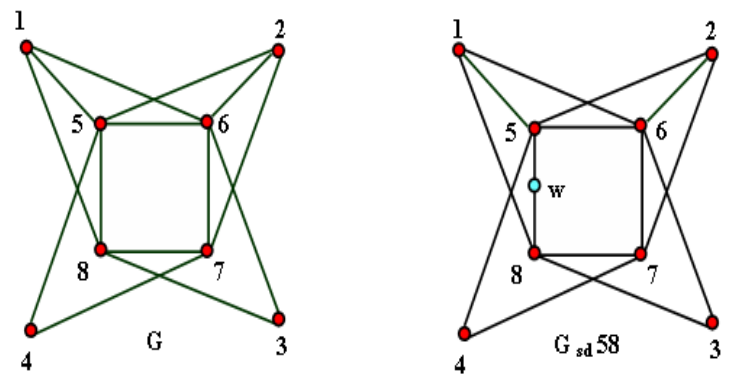

Figure 1. $G$ is dss. Here $d(G)=|\{5,6\},\{8,2,4\},\{1,7,3\}|=3$ and $d\left(G_{\text {sd }} 58\right)=|\{4, w, 6\},\{5,2,3\},\{1,7,8\}|=3$. This is true for all uv $\in$ $\mathrm{E}(\mathrm{G})$. Let $\mathrm{S}=\{5,6,7,8\} \subseteq \mathrm{V}(\mathrm{G}) .<\mathrm{S}>=\mathrm{C}_{4}$ in $\mathrm{G}$.

Yamuna, $\mathrm{M}$ and Karthika, K [6], have proved the following 
results,

$R_{1}$. Let $G$ be any graph. Then $d\left(G_{s d} u v\right) \leq 3$.

$R_{2}$. When $d(G)=3, d\left(G_{s d}\right.$ uv $)=3$ if and only if there is a partition $Z=\left\{V_{1}, V_{2}, V_{3}\right\}$ for $G$ such that

i. $\quad \mathrm{V}_{1}$ and $\mathrm{V}_{2}$ are dominating sets for $\mathrm{G}$ such that $\mathrm{u} \in \mathrm{V}_{1}$, $\mathrm{V} \in \mathrm{V}_{2}$.

ii. $\quad \mathrm{v}$ is $2-$ dominated with respect to $\mathrm{V}_{1}$.

iii. $\quad \mathrm{u}$ is $2-$ dominated with respect to $\mathrm{V}_{2}$.

iv. $\mathrm{V}_{3}$ dominates atleast $\mathrm{G}-\{\mathrm{u}\}-\{\mathrm{v}\}$.

$R_{3}$. When $d(G)=2, d\left(G_{s d} u v\right)=3$ if and only if there is a domatic partition $\mathrm{d}(\mathrm{G})=\left|\left\{\mathrm{V}_{1}\right\},\left\{\mathrm{V}_{2}\right\}\right|, \mathrm{u} \in \mathrm{V}_{1}, \mathrm{v} \in \mathrm{V}_{2}$ such that

i. $\quad \mathrm{V}$ is $2-$ dominated with respect to $\mathrm{V}_{1}$.

ii. $\quad V_{2}=V_{12} \cup V_{22}$, where

a. $\quad \mathrm{v} \in \mathrm{V}_{12}$, $\mathrm{u}$ is 2 - dominated with respect to $\mathrm{V}_{12}$.

b. $\quad V_{22}$ does not dominate atleast one of $u$ or $v$, that is $V_{22}$ is a dominating set for $\mathrm{G}-\{\mathrm{u}\}-\{\mathrm{v}\}$.

\section{Results and Discussion}

\section{Minimal Dominating Sets and dss Graphs}

In this section we provide results relating domatic subdivision stable graphs and minimal properties of the dominating sets.

Theorem 1

Let $d(G)=2$ and $d\left(G_{s d}\right.$ uv $)=3$. There is a domatic partition for $G$ such that atleast one $V_{i}, i=1,2$ is not minimal.

Proof

Let $d(G)=2$ and $d\left(G_{s d} u v\right)=3=\left|\left\{V_{1}\right\},\left\{V_{2}\right\},\left\{V_{3}\right\}\right|$. By result $R_{3}, V_{1}, V_{2} \cup V_{3}-\{w\}$ are dominating set for $G$, such that $V_{2} \cup V_{3}-\{w\}$ is not minimal, since $V_{2}$ itself is a dominating set.

If $\left|\mathrm{V}_{3}-\{\mathrm{w}\}\right| \geq 2$, then $\mathrm{V}_{1} \cup \mathrm{V}_{13}, \mathrm{~V}_{2} \cup \mathrm{V}_{23}$ are dominating set for $\mathrm{G}$, where $\left\{\mathrm{V}_{13}, \mathrm{~V}_{23}\right\}$ is a partition for $\mathrm{V}_{3}-\{\mathrm{w}\}$. This implies, there is a partition for $G$ say $d(G)=\mid\left\{V_{1} \cup V_{13}\right\}$, $\left\{V_{2} \cup V_{23}\right\} \mid$, such that both the sets in the partition are not minimal.

Theorem 2

If $\mathrm{d}(\mathrm{G})=\left|\left\{\mathrm{V}_{1}\right\},\left\{\mathrm{V}_{2}\right\}\right|$ such that $\mathrm{V}_{1}$ and $\mathrm{V}_{2}$ are both minimal for all possible domatic partition for $G$, then $d\left(G_{s d}\right.$ uv $) \neq 3$.

Proof

If $d\left(G_{\text {sd }}\right.$ uv $)=3$, say d $\left(G_{\text {sd }}\right.$ uv $)=\left|\left\{U_{1}\right\},\left\{U_{2}\right\},\left\{U_{3}\right\}\right|$, then by $\mathrm{R}_{1}$, let us assume that, $\mathrm{u} \in \mathrm{U}_{1}, \mathrm{v} \in \mathrm{U}_{2}, \mathrm{w} \in \mathrm{U}_{3} . \mathrm{U}_{1}, \mathrm{U}_{2}$, $\mathrm{U}_{3}-\{\mathrm{w}\}$ are dominating sets for $\mathrm{G}$ also. Then $\mathrm{d}(\mathrm{G})=1$ $\left\{\mathrm{U}_{1}\right\},\left\{\mathrm{U}_{2}\right\} \cup\left\{\mathrm{U}_{3}-\{\mathrm{w}\}\right\} \mid$ is a domatic partition for $\mathrm{G}$ such that $U_{2} \cup\left\{\left\{U_{3}\right\}-\{w\}\right\}$ is not minimal, a contradiction to our assumption.

Theorem 3

When $d(G)=2, d\left(G_{s d}\right.$ uv $)=2$ if for all possible partition $d$ $(\mathrm{G})=\left|\left\{\mathrm{V}_{1}\right\},\left\{\mathrm{V}_{2}\right\}\right|$ if $\mathrm{V}_{\mathrm{i}}$ is not minimal, $\mathrm{i}=1,2$, then

i. If $\mathrm{V}_{\mathrm{i} 1}$ is a dominating set for $\mathrm{G}, \mathrm{V}_{\mathrm{i} 2}$ does not dominate $\mathrm{G}-\{\mathrm{u}\}-\{\mathrm{v}\}$, where $\mathrm{V}_{\mathrm{i}}=\mathrm{V}_{\mathrm{i} 1} \cup \mathrm{V}_{\mathrm{i} 2}$.

ii. $\mathrm{V}_{12} \cup \mathrm{V}_{22}$ does not dominate $\mathrm{G}-\{\mathrm{u}\}-\{\mathrm{v}\}$.
Proof

Let $d(G)=\left|\left\{V_{1}\right\},\left\{V_{2}\right\}\right|$ such that atleast one $V_{i}$ is not minimal satisfying the conditions of the theorem.

Let $\mathrm{V}_{1}=\left\{\mathrm{V}_{11} \cup \mathrm{V}_{12}\right\}$ and $\mathrm{V}_{2}=\left\{\mathrm{V}_{21} \cup \mathrm{V}_{22}\right\}$. Assume that $\mathrm{V}_{11}$ and $\mathrm{V}_{21}$ are minimal dominating sets for $\mathrm{G}$. Given that $\mathrm{V}_{12}, \mathrm{~V}_{22}$ and $\mathrm{V}_{12} \cup \mathrm{V}_{22}$ does not dominate $\mathrm{G}-\{\mathrm{u}\}-\{\mathrm{v}\}$. In this case, $d\left(G_{s d} u v\right) \neq 3$. Suppose $d\left(G_{s d} u v\right)=3$, say d $\left(\mathrm{G}_{\mathrm{sd}} \mathrm{uv}\right)=\left|\left\{\mathrm{U}_{1}\right\},\left\{\mathrm{U}_{2}\right\},\left\{\mathrm{U}_{3}\right\}\right|$. Then as in Theorem 2, $\mathrm{d}$ $(\mathrm{G})=\left|\left\{\mathrm{U}_{1}\right\},\left\{\mathrm{U}_{2} \cup\left\{\mathrm{U}_{3}-\{\mathrm{w}\}\right\}\right\}\right|$ is a domatic partition for $G$ such that $U_{3}-\{w\}$ dominates $G-\{u\}-\{v\}$, a contradiction to the hypothesis of the theorem. Since $d\left(G_{s d}\right.$ $\mathrm{uv}) \neq 3, \mathrm{~d}\left(\mathrm{G}_{\mathrm{sd}} \mathrm{uv}\right)=2$.

Theorem 4

Let $d(G)=2$ such that

i. Atleast one of $\mathrm{V}_{\mathrm{i}}$ is not minimal.

ii. $\mathrm{V}_{11}, \mathrm{~V}_{21}$ are minimal dominating sets for $\mathrm{G}$, where $\mathrm{V}_{1}$ $=\left\{\mathrm{V}_{11} \cup \mathrm{V}_{12}\right\}$ and $\mathrm{V}_{2}=\left\{\mathrm{V}_{21} \cup \mathrm{V}_{22}\right\}$.

iii. $\mathrm{V}_{12}, \mathrm{~V}_{22}$ dominates $\mathrm{G}-\{\mathrm{u}\}-\{\mathrm{v}\}$.

Then there is atleast one partition for $G$, where $u$, v does not belong to the same partition.

Proof

Assume that $\mathrm{u}, \mathrm{v}$ belong to the same partition for every possible domatic partition for $G$, say $u, v \in V_{1}$, where $d(G)$ $=\left|\left\{V_{1}\right\},\left\{V_{2}\right\}\right|$.

Case $\mathrm{i} \mathrm{V}_{2}$ is not minimal

Let $\mathrm{V}_{2}=\mathrm{V}_{21} \cup \mathrm{V}_{22}$, where $\mathrm{V}_{21}$ is a dominating set and $\mathrm{V}_{22}$ dominates $\mathrm{G}-\{\mathrm{u}\}-\{\mathrm{v}\}$. Let $\mathrm{V}_{3}=\left\{\mathrm{V}_{22} \cup\{\mathrm{u}\}\right\}$ and $\mathrm{V}_{4}=$ $\left\{\mathrm{V}_{21} \cup\left\{\mathrm{V}_{1}-\{\mathrm{u}\}\right\}\right\}$.

Case ii $V_{1}$ is not minimal

Let $V_{1}=V_{11} \cup V_{12}$, where $V_{11}$ is a dominating set for $G, V_{12}$ dominates $\mathrm{G}-\{\mathrm{u}\}-\{\mathrm{v}\}$. Then $\mathrm{u}, \mathrm{v} \in \mathrm{V}_{11}$. Let $\mathrm{V}_{3}=\left\{\mathrm{V}_{12}\right.$ $\cup \mathrm{u}\}, \mathrm{V}_{4}=\left\{\left\{\mathrm{V}_{11}-\{\mathrm{u}\}\right\} \cup\left\{\mathrm{V}_{2}\right\}\right\}$.

Case iii $V_{1}$ and $V_{2}$ are both not minimal

Let $\mathrm{V}_{1}=\left\{\mathrm{V}_{11} \cup \mathrm{V}_{12}\right\}$ and $\mathrm{V}_{2}=\left\{\mathrm{V}_{21} \cup \mathrm{V}_{22}\right\}$, where $\mathrm{V}_{11}$ and $\mathrm{V}_{21}$ are minimal dominating sets for $\mathrm{G}$. Let $\mathrm{V}_{12}, \mathrm{~V}_{22}$ dominate $\mathrm{G}-\{\mathrm{u}\}-\{\mathrm{v}\}, \mathrm{u}, \mathrm{v} \in \mathrm{V}_{11}$. Let $\mathrm{V}_{3}=\left\{\mathrm{V}_{12} \cup\{\mathrm{u}\}\right\}, \mathrm{V}_{4}=\left\{\left\{\mathrm{V}_{11}\right.\right.$ $\left.-\{\mathrm{u}\}\} \cup\left\{\mathrm{V}_{2}\right\}\right\}$.

In all three cases $d(G)=\left|\left\{V_{3}\right\},\left\{V_{4}\right\}\right|$ is a domatic partition for $G$ such that $u \in V_{3}, v \in V_{4}$, a contradiction.

Hence there is atleast one partition for $G$, where $u$, $v$ does not belong to the same partition.

Theorem 5

Let $\mathrm{d}(\mathrm{G})=3$. If for any $\mathrm{u} v \in \mathrm{E}(\mathrm{G})$, there is a domatic partition $d(G)=\left|\left\{V_{1}\right\},\left\{V_{2}\right\},\left\{V_{3}\right\}\right|$ such that

i. $u \in V_{1}, v \in V_{2}$,

ii. $\quad \mathrm{u}$ is selfish with respect to $\mathrm{V}_{1}$,

iii. $\quad \mathrm{V}$ is selfish with respect to $\mathrm{V}_{2}$,

then $\mathrm{d}\left(\mathrm{G}_{\mathrm{sd}} \mathrm{uv}\right)=3$.

Proof

Let $d(G)=3$ and $u v \in E(G)$. Let $d(G)=\mid\left\{V_{1}\right\},\left\{V_{2}\right\}$, $\left\{V_{3}\right\} \mid$ such that the conditions of the theorem is satisfied. Then,

When $\mathrm{u} \in \mathrm{V}_{1}$, $\mathrm{v}$ is 2 - dominated.

When $\mathrm{v} \in \mathrm{V}_{2}$, $\mathrm{u}$ is $2-$ dominated.

$\mathrm{V}_{3}$ dominate $\mathrm{G}-\{\mathrm{u}\}-\{\mathrm{v}\}$.

By $R_{2}, d\left(G_{s d} u v\right)=3$. Also d $\left(G_{s d} u v\right)=\mid\left\{V_{1}\right\},\left\{V_{2}\right\}$, $\left\{\mathrm{V}_{3} \cup\{\mathrm{w}\}\right\} \mid$. 
Remark

If $\mathrm{G}$ is a graph such that $\mathrm{d}(\mathrm{G})=3$ and the conditions of the Theorem 5 is satisfied for all $u v \in E(G)$, then $G$ is dss.

Theorem 6

Let $d(G)=\left|\left\{V_{1}\right\},\left\{V_{2}\right\}, \ldots,\left\{V_{k}\right\}\right|$. If $G$ is a graph such that $d(G)=k$ only if exactly one of $V_{i}$ is a $\gamma$ - set, then every $\mathrm{V}_{\mathrm{i}}, \mathrm{i}=1,2, \ldots, \mathrm{k}$ are minimal dominating set.

Proof

Let $\mathrm{d}(\mathrm{G})=\left|\left\{\mathrm{V}_{1}\right\},\left\{\mathrm{V}_{2}\right\}, \ldots,\left\{\mathrm{V}_{\mathrm{k}}\right\}\right|$ be a domatic partition for $\mathrm{G}$ satisfying the conditions of the theorem.

Let $V_{i}$ be the $\gamma$ - set for $G$. Assume that there is one $V_{j}, j \neq i, j$ $=1,2, \ldots, \mathrm{k}$ that is not minimal. Let $\mathrm{V}_{\mathrm{j}}=\mathrm{V}_{\mathrm{j} 1} \cup \mathrm{V}_{\mathrm{j} 2}$ such that $\mathrm{V}_{\mathrm{j} 1}$ is a minimal dominating set. Then $\mathrm{V}_{1}, \mathrm{~V}_{2}, \ldots, \mathrm{V}_{\mathrm{i}} \cup$ $V_{j 2}, \ldots, V_{j}-V_{j 2}, \ldots, V_{k}$ is a domatic partition for $G$ such that $\mathrm{d}(\mathrm{G})=\mathrm{k}$, which contains no $\gamma$ - set, a contradiction to our assumption.

\section{Generating New dss Graphs Using Graph Operations}

In this section we show that every graph is an induced subgraph of a dss graph, and discuss two methods of generating new dss graphs from existing dss graphs.

Theorem 7

Any tree is dss.

Proof

Let $\mathrm{T}$ be any tree. We know that, $\mathrm{d}(\mathrm{T})=2$ always. $\mathrm{d}\left(\mathrm{T}_{\mathrm{sd}}\right.$ uv $)$ is also a tree. We know that for any graph $\mathrm{d}(\mathrm{G}) \leq \delta+1$, which implies $\mathrm{d}\left(\mathrm{T}_{\mathrm{sd}} \mathrm{uv}\right)=(\mathrm{V}, \mathrm{V}-\mathrm{D})=2$, for all $\mathrm{uv} \in \mathrm{E}$ ( $G$ ). Hence any tree is a dss graph.

Remark

1. Let $\mathrm{G}$ be any graph such that $\mathrm{G}$ has atleast one pendant vertex. Then $\mathrm{G}$ is a dss graph.

2. If $G$ has more than one pendant vertex then $G-v$ is also a dss graph, for all $\mathrm{u}, \mathrm{v} \in \mathrm{V}(\mathrm{G})$.

Theorem 8

Every graph is an induced subgraph of a dss graph $\mathrm{H}$ such that $\mathrm{d}(\mathrm{H})=2$.

Proof

Consider $\mathrm{G}_{\mathrm{o}} \mathrm{K}_{1}$, for any connected graph $\mathrm{G}$ with $\mathrm{n}$ - vertices. Let $\mathrm{H}=\mathrm{G}$ o $\mathrm{K}_{1}$. $\mathrm{H}$ and $\mathrm{H}_{\mathrm{sd}} \mathrm{uv}$ has atleast one pendant vertex, for all $u v \in E(H)$. This implies, $d(H)=d\left(H_{s d} u v\right)=2$, for all $u v \in E(H)$. By Remark 1, every graph is an induced subgraph of a dss graph $\mathrm{H}$ such that $\mathrm{d}(\mathrm{H})=2$.

Theorem 9

Every graph is an induced subgraph of a dss graph $\mathrm{H}$ such that $\mathrm{d}(\mathrm{H})=3$.

Proof

Let $G$ be a graph with $n-$ vertices. Let $V(G)=\left\{v_{1}, v_{2}, \ldots\right.$, $\left.\mathrm{v}_{\mathrm{n}}\right\}$. Consider $\mathrm{n}-$ copies of the complete graph $\mathrm{K}_{3}: \mathrm{y}_{\mathrm{i}} \mathrm{w}_{\mathrm{i}} \mathrm{u}_{\mathrm{i}}, \mathrm{i}=$ $1,2, \ldots, n$. Merge $v_{i}$ with $u_{i}$ and label the new vertex as $x_{i}, i=$ $1,2, \ldots, \mathrm{n}$. We include the following edges.

$\mathrm{y}_{1} \mathrm{y}_{2}, \mathrm{y}_{2} \mathrm{y}_{3}, \ldots, \mathrm{y}_{\mathrm{n}-1} \mathrm{y}_{\mathrm{n}}, \mathrm{y}_{\mathrm{n}} \mathrm{y}_{1}$ and $\mathrm{x}_{1} \mathrm{y}_{2}, \mathrm{x}_{2} \mathrm{y}_{3}, \ldots, \mathrm{x}_{\mathrm{n}-1} \mathrm{y}_{\mathrm{n}}, \mathrm{x}_{\mathrm{n}} \mathrm{y}_{1}$, that is $\mathrm{V}(\mathrm{H})=\left\{\mathrm{x}_{\mathrm{i}}, \mathrm{y}_{\mathrm{i}}, \mathrm{w}_{\mathrm{i}}\right\}, \mathrm{i}=1,2, \ldots, \mathrm{n}$, which implies $\mid \mathrm{V}$ $(\mathrm{H}) \mid=3 \mathrm{n}, \mathrm{E}(\mathrm{H})=\mathrm{E}(\mathrm{G}) \cup\left\{\mathrm{x}_{\mathrm{i}} \mathrm{y}_{\mathrm{i}}, \mathrm{x}_{\mathrm{i}} \mathrm{w}_{\mathrm{i}}, \mathrm{w}_{\mathrm{i}} \mathrm{y}_{\mathrm{i}}\right\} \cup\left\{\mathrm{x}_{1} \mathrm{y}_{2}\right.$, $\left.\mathrm{x}_{2} \mathrm{y}_{3}, \ldots, \mathrm{x}_{\mathrm{n}-1} \mathrm{y}_{\mathrm{n}}, \mathrm{x}_{\mathrm{n}} \mathrm{y}_{1}\right\} \cup\left\{\mathrm{y}_{1} \mathrm{y}_{2}, \mathrm{y}_{2} \mathrm{y}_{3}, \ldots, \mathrm{y}_{\mathrm{n}-1} \mathrm{y}_{\mathrm{n}}, \mathrm{y}_{\mathrm{n}} \mathrm{y}_{1}\right\}$, that is $|\mathrm{E}(\mathrm{H})|=|\mathrm{E}(\mathrm{G})|+5 \mathrm{n}$.

Let $X=\left\{x_{1}, x_{2}, \ldots, x_{n}\right\}, Y=\left\{y_{1}, y_{2}, \ldots, y_{n}\right\}$ and $W=\left\{w_{1}\right.$, $\left.\mathrm{w}_{2}, \ldots, \mathrm{w}_{\mathrm{n}}\right\}$. As $\mathrm{P}_{3}: \mathrm{x}_{\mathrm{i}} \mathrm{w}_{\mathrm{i}} \mathrm{y}_{\mathrm{i}}, \mathrm{i}=1,2, \ldots, \mathrm{n}$ are subgraphs of $\mathrm{H}$, By $\mathrm{R}_{1}, \mathrm{~d}(\mathrm{H}) \leq 3$. Also $\mathrm{d}(\mathrm{H})=|\{\mathrm{X}\},\{\mathrm{Y}\},\{\mathrm{W}\}|=3$. Let $\mathrm{d}\left(\mathrm{H}_{\mathrm{sd}} \mathrm{uv}\right)=\mathrm{w}$, for all $\mathrm{uv} \in \mathrm{E}(\mathrm{G})$.

$\mathrm{d}\left(\mathrm{H}_{\mathrm{sd}} \mathrm{y}_{\mathrm{i}} \mathrm{w}_{\mathrm{i}}\right)=\mid\left\{\mathrm{w}_{\mathrm{i}}, \mathrm{X}-\left\{\mathrm{x}_{\mathrm{i}}\right\}\right\},\left\{\mathrm{w}, \mathrm{Y}-\left\{\mathrm{y}_{\mathrm{i}}\right\}\right\},\left\{\mathrm{y}_{\mathrm{i}}, \mathrm{x}_{\mathrm{i}}, \mathrm{W}\right.$ $\left.-\left\{\mathrm{w}_{\mathrm{i}}\right\}\right\} \mid=3$, for all $\mathrm{i}=1,2, \ldots, \mathrm{n}$.

$\mathrm{d}\left(\mathrm{H}_{\mathrm{sd}} \mathrm{w}_{\mathrm{i}} \mathrm{x}_{\mathrm{i}}\right)=\mid\left\{\mathrm{y}_{\mathrm{i}}, \mathrm{x}_{\mathrm{i}}, \mathrm{W}-\left\{\mathrm{w}_{\mathrm{i}}\right\}\right\},\left\{\mathrm{w}, \mathrm{X}-\left\{\mathrm{x}_{\mathrm{i}}\right\}\right\},\left\{\mathrm{w}_{\mathrm{i}}, \mathrm{Y}\right.$ $\left.-\left\{y_{i}\right\}\right\} \mid=3$, for all $\mathrm{i}=1,2, \ldots, \mathrm{n}$.

$\mathrm{d}\left(\mathrm{H}_{\mathrm{sd}} \mathrm{x}_{\mathrm{i}} \mathrm{y}_{\mathrm{i}}\right)=\mathrm{d}\left(\mathrm{H}_{\mathrm{sd}} \mathrm{x}_{\mathrm{i}} \mathrm{y}_{\mathrm{j}}\right)=|\{\mathrm{X}\},\{\mathrm{Y}\},\{\mathrm{w}, \mathrm{W}\}|=3$, for all $\mathrm{i} \neq \mathrm{j}, \mathrm{i}, \mathrm{j}=1,2, \ldots, \mathrm{n}$.

$\mathrm{d}\left(\mathrm{H}_{\mathrm{sd}} \mathrm{y}_{\mathrm{i}} \mathrm{y}_{\mathrm{j}}\right)=\mid\left\{\mathrm{y}_{\mathrm{i}}, \mathrm{X}-\left\{\mathrm{x}_{\mathrm{i}}\right\}\right\},\left\{\mathrm{y}_{\mathrm{j}}, \mathrm{W}-\left\{\mathrm{w}_{\mathrm{j}}\right\}\right\},\left\{\mathrm{w}, \mathrm{w}_{\mathrm{j}}, \mathrm{x}_{\mathrm{i}}\right.$, $\left.Y-\left\{y_{i}\right\}-\left\{y_{j}\right\}\right\} \mid=3$, for all $i \neq j, i, j=1,2, \ldots, n$.

$\mathrm{d}\left(\mathrm{H}_{\mathrm{sd}} \mathrm{x}_{\mathrm{i}} \mathrm{x}_{\mathrm{j}}\right)=\mid\left\{\mathrm{x}_{\mathrm{i}}, \mathrm{Y}-\left\{\mathrm{y}_{\mathrm{i}}\right\}\right\},\left\{\mathrm{x}_{\mathrm{j}}, \mathrm{W}-\left\{\mathrm{w}_{\mathrm{j}}\right\}\right\},\left\{\mathrm{w}, \mathrm{w}_{\mathrm{j}}, \mathrm{y}_{\mathrm{i}}\right.$, $\left.X-\left\{x_{i}\right\}-\left\{x_{j}\right\}\right\} \mid=3$, for all $i \neq j, i, j=1,2, \ldots, n$. This implies, $d\left(H_{s d} u v\right)=3$, for all $u v \in E(H)$, that is $d(H)=$ $\mathrm{d}\left(\mathrm{H}_{\mathrm{sd}} \mathrm{uv}\right)=3$.

Hence every graph is an induced subgraph of a dss graph $\mathrm{H}$ such that $\mathrm{d}(\mathrm{H})=3$.

Example
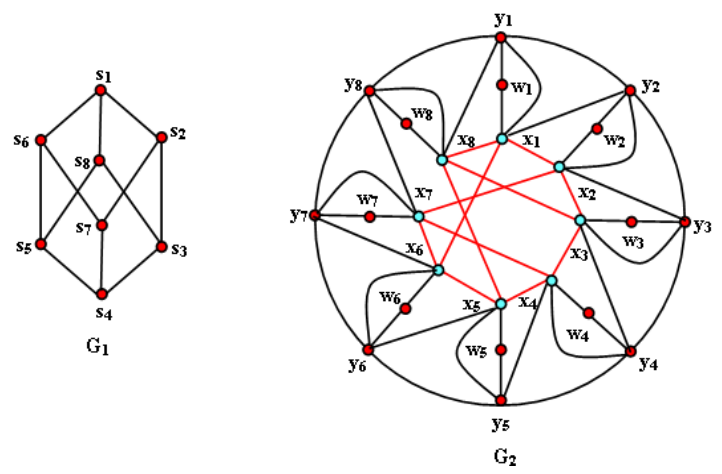

Figure 2. $\mathrm{G}_{1}$ is not dss. Also $<\mathrm{x}_{1}, \mathrm{x}_{2}, \ldots, \mathrm{x}_{8}>=\mathrm{G}_{1}$ in $\mathrm{G}_{2}$. The induced subgraph is shown in red lines.

Vestergaard, P. D and Zelinka. B. [2], have provided the following result.

Let $G$ be the union of two graphs $G_{1}$ and $G_{2}$ having exactly one common vertex $\mathrm{a}$; this vertex $\mathrm{a}$ is the cut vertex of $\mathrm{G}$. The graph obtained from $G_{1}$ and $G_{2}$ by deleting a will be denoted respectively by $\mathrm{G}_{1}{ }^{\prime}, \mathrm{G}_{2}{ }^{\prime}$.

$\mathrm{R}_{4}$. With the above notation, for every graph $\mathrm{G}$, the domatic numbers satisfy

$\min \left\{\mathrm{d}\left(\mathrm{G}_{1}\right), \mathrm{d}\left(\mathrm{G}_{2}\right)\right\} \leq \mathrm{d}(\mathrm{G}) \leq 1+\min \left\{\mathrm{d}\left(\mathrm{G}_{1}{ }^{\prime}\right), \mathrm{d}\right.$ $\left.\left(\mathrm{G}_{2}{ }^{\prime}\right)\right\}$.

They define a saturated vertex as follows

\section{Saturated Vertex}

A vertex $x$ of a graph $G$ is called saturated, if it is adjacent to all other vertices of $G$. For example in the complete graph $\mathrm{K}_{\mathrm{n}}$ every vertex is saturated.

Theorem 10

Let $G_{1}$ and $G_{2}$ be two graphs such that $d\left(G_{1}\right)=d\left(G_{2}\right)=k$. Let $\mathrm{u} \in \mathrm{V}\left(\mathrm{G}_{1}\right), \mathrm{v} \in \mathrm{V}\left(\mathrm{G}_{2}\right)$ such that $\mathrm{d}\left(\mathrm{G}_{1}-\{\mathrm{u}\}\right)=\mathrm{d}$ $\left(G_{1}\right), d\left(G_{2}-\{v\}\right)=d\left(G_{2}\right)$. Let $G$ be the graph obtained by merging vertex $u$ and $v$. Then $d(G)=k$.

Proof

Let $G_{1}$ and $G_{2}$ be two graphs such that $d\left(G_{1}\right)=d\left(G_{2}\right)=k$. 
Let $\mathrm{u} \in \mathrm{V}\left(\mathrm{G}_{1}\right), \mathrm{v} \in \mathrm{V}\left(\mathrm{G}_{2}\right)$ such that $\mathrm{d}\left(\mathrm{G}_{1}\right)=\mathrm{d}\left(\mathrm{G}_{2}\right)=\mathrm{k}$. Let $\mathrm{u} \in \mathrm{V}\left(\mathrm{G}_{1}\right), \mathrm{v} \in \mathrm{V}\left(\mathrm{G}_{2}\right)$ such that $\mathrm{d}\left(\mathrm{G}_{1}-\{\mathrm{u}\}\right)=\mathrm{d}$ $\left(G_{1}\right), d\left(G_{2}-\{v\}\right)=d\left(G_{2}\right)$. Let $G$ be the graph obtained by merging vertex $\mathrm{u}$ and $\mathrm{v}$.

Claim 1

If $d(G)=d(G-\{u\})$, for some $u \in V(G)$, then $u$ cannot be a saturated vertex.

Proof

If possible assume that $u$ is a saturated vertex. Since $d(G)=$ $\mathrm{d}(\mathrm{G}-\{\mathrm{u}\})=\mathrm{k}$ (say), there are $\mathrm{k}$ - dominating sets $\mathrm{V}_{1}$, $V_{2}, \ldots, V_{k}$ for $G-\{u\}$. Since $u$ is a saturated vertex, $V_{1}$, $\mathrm{V}_{2}, \ldots, \mathrm{V}_{\mathrm{k}}$ are dominating sets for $\mathrm{G}$ also, which implies $\mathrm{V}_{1}$, $\mathrm{V}_{2}, \ldots, \mathrm{V}_{\mathrm{k}}, \mathrm{u}$ are all dominating sets for $\mathrm{G}$. This implies $\mid \mathrm{d}$ ( $G) \mid>k$, a contradiction. So, if $d(G)=d(G-\{u\})$, for any graph $\mathrm{G}, \mathrm{u}$ is not a saturated vertex.

From Claim 1, we conclude that $\mathrm{u}$ and $\mathrm{v}$ are not saturated vertices with respect to $G_{1}$ and $G_{2}$.

Since uv is a cut vertex, we observe that, if $U_{1}$ is a dominating set for $\mathrm{G}$, then $\mathrm{U}_{1}$ can be partition as

$$
\mathrm{U}_{1}= \begin{cases}\mathrm{U}_{11} \cup \mathrm{U}_{12} \cup\{\mathrm{uv}\}, & \text { if } \mathrm{uv} \in \mathrm{U}_{1} \\ \mathrm{U}_{11} \cup \mathrm{U}_{12}, & \text { if } \mathrm{uv} \notin \mathrm{U}_{1}\end{cases}
$$

where $\mathrm{V}\left(\mathrm{U}_{11}\right) \subseteq \mathrm{V}\left(\mathrm{G}_{1}\right), \mathrm{U}_{12} \subseteq \mathrm{V}\left(\mathrm{G}_{2}\right)$.

Also we observe that, $\mathrm{U}_{11} \cup\{\mathrm{u}\}, \mathrm{U}_{12} \cup\{\mathrm{v}\}$ are dominating sets for $G_{1}$ and $G_{2}$ respectively, if $u v \in U_{1}$. $U_{11}$, $\mathrm{U}_{12}$ are dominating sets for $\mathrm{G}_{1}$ and $\mathrm{G}_{2}$ respectively, if $\mathrm{uv} \notin$ $\mathrm{U}_{1}$. Since $\mathrm{d}\left(\mathrm{G}_{1}-\{\mathrm{u}\}\right)=\mathrm{d}\left(\mathrm{G}_{2}-\{\mathrm{v}\}\right)=\mathrm{k}$, by $\mathrm{R}_{4}, \mathrm{~d}(\mathrm{G})$ $\leq \mathrm{k}+1$.

Claim 2

$$
\mathrm{d}(\mathrm{G}) \neq \mathrm{k}+1 \text {. }
$$

Proof

If possible, let $\mathrm{d}(\mathrm{G})=\mathrm{k}+1=\mid\left\{\mathrm{V}_{1}\right\},\left\{\mathrm{V}_{2}\right\}, \ldots,\left\{\mathrm{V}_{\mathrm{k}}\right\}$, $\left\{\mathrm{V}_{\mathrm{k}+1}\right\} \mid$. Let $\mathrm{V}_{\mathrm{i}}=\mathrm{V}_{\mathrm{i} 1} \cup \mathrm{V}_{\mathrm{i} 2}$, where $\mathrm{V}_{\mathrm{i} 1}=\mathrm{V}\left(\mathrm{G}_{1}\right)-\{\mathrm{u}\}, \mathrm{V}_{\mathrm{i} 2}$ $=\mathrm{V}\left(\mathrm{G}_{2}\right)-\{\mathrm{v}\}$. Let $\mathrm{uv} \in \mathrm{V}_{1}$. By claim 1, there is atleast one vertex say $\mathrm{u}_{1} \in \mathrm{G}_{1}, \mathrm{v}_{1} \in \mathrm{G}_{2}$ such that $\mathrm{uv}, \mathrm{u}_{1}, \mathrm{v}_{1} \in \mathrm{V}_{1}$. $\left\{\mathrm{V}_{11} \cup\right.$ $\left.\{\mathrm{u}\}, \mathrm{V}_{21}, \ldots, \mathrm{V}_{\mathrm{k} 1}, \mathrm{~V}_{(\mathrm{k}+1) 1}\right\}$ is a domatic partition for $\mathrm{G}_{1}$, since $\mathrm{V}_{21}, \mathrm{~V}_{31}, \ldots, \mathrm{V}_{\mathrm{k} 1}, \mathrm{~V}(\mathrm{k}+1) 1$ dominates $\mathrm{G}_{1}$, a contradiction as $\mathrm{d}\left(\mathrm{G}_{1}\right)=\mathrm{k}$. This implies, $\mathrm{d}(\mathrm{G}) \neq \mathrm{k}+1$.

By claim 2, we conclude that $\mathrm{d}(\mathrm{G})=\mathrm{k}$.

Converse of Theorem 10 need not be true.

Example

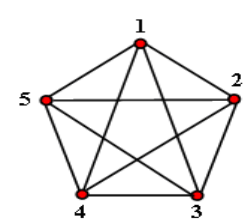

$\mathrm{G}_{1}$

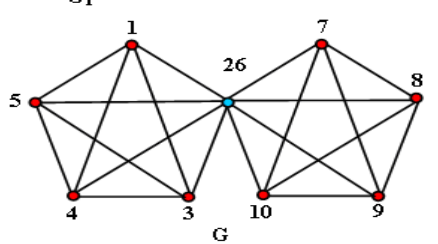

Figure 3. $\mathrm{d}(\mathrm{G})=\mathrm{d}\left(\mathrm{G}_{1}\right)=\mathrm{d}\left(\mathrm{G}_{2}\right)=5$, but $\mathrm{d}\left(\mathrm{G}_{1}-\{\mathrm{u}\}\right)=\mathrm{d}\left(\mathrm{G}_{2}-\{\mathrm{v}\}\right)$ $=4$, that is $d\left(G_{1}\right) \neq d\left(G_{1}-\{u\}\right)$ and $d\left(G_{2}\right) \neq d\left(G_{2}-\{v\}\right)$.

Theorem 11
If $\mathrm{G}_{1}$ and $\mathrm{G}_{2}$ are dss graphs such that $\mathrm{d}\left(\mathrm{G}_{1}\right)=\mathrm{d}\left(\mathrm{G}_{2}\right)=3$, $\mathrm{d}\left(\mathrm{G}_{1}\right)=\mathrm{d}\left(\mathrm{G}_{1}-\{\mathrm{u}\}\right), \mathrm{d}\left(\mathrm{G}_{2}\right)=\mathrm{d}\left(\mathrm{G}_{2}-\{\mathrm{v}\}\right)$, for some $\mathrm{u} \in \mathrm{V}_{1}, \mathrm{v} \in \mathrm{V}_{2}$, then the graph $\mathrm{G}$ obtained by merging $\mathrm{u}$ and $\mathrm{v}$ is also dss.

Proof

By Theorem 10, we know that $d(G)=3$. Let $G_{s d} x y=w$, for some $x y \in E(G)$. Let $e=x y \in E(G)$, either $e \in E\left(G_{1}\right)$ or e $\in \mathrm{E}\left(\mathrm{G}_{2}\right)$. Assume that $\mathrm{e} \in \mathrm{E}\left(\mathrm{G}_{1}\right)$.

Since $\mathrm{G}_{1}$ is dss, let $d\left(\mathrm{G}_{1 \text { sd }} \mathrm{xy}\right)=\mid\left\{\mathrm{U}_{1}\right\},\left\{\mathrm{U}_{2}\right\},\left\{\mathrm{U}_{3}\right\}$ |such that $u \in U_{1}$. Since $d\left(G_{2}\right)=3$, let $d\left(G_{2}\right)=\mid\left\{C_{1}\right\}$, $\left\{\mathrm{C}_{2}\right\},\left\{\mathrm{C}_{3}\right\} \mid$ such that $\mathrm{v} \in \mathrm{C}_{1}$. Then $\left\{\mathrm{U}_{1} \cup \mathrm{C}_{1}-\{\mathrm{u}\}-\{\mathrm{v}\}\right.$ $\left.\cup\{\mathrm{uv}\}, \mathrm{U}_{2} \cup \mathrm{C}_{2}, \mathrm{U}_{3} \cup \mathrm{C}_{3}\right\}$ is a domatic partition for $\mathrm{G}_{\mathrm{sd}} \mathrm{xy}$, which implies $d\left(G_{s d} x y\right) \geq 3$. Since $P_{3}$ : xwy is a subgraph of $G$, by $R_{1}$, we know that $d\left(G_{s d} x y\right) \leq 3$. This implies $d\left(G_{s d}\right.$ $\mathrm{xy})=3$. This is true for every $\mathrm{e} \in \mathrm{E}(\mathrm{G})$, that is $\mathrm{G}$ is dss.

Example

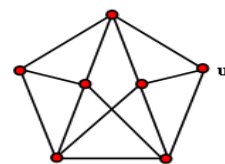

$\mathrm{G}_{1}$

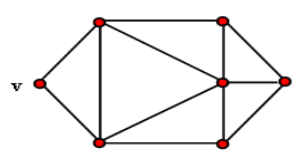

$\mathbf{G}_{2}$

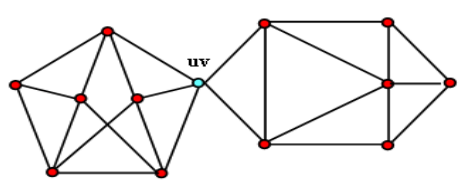

G
Figure 4. $d\left(G_{1}\right)=d\left(G_{1 s d} x y\right)=3, x y \in E\left(G_{1}\right)$ and $d\left(G_{2}\right)=d\left(G_{2 s d} x y\right)$ $=3, x y \in E\left(G_{2}\right)$. Here $d(G)=d\left(G_{s d} a b\right)=3$, for all $a b \in E(G)$.

Converse of Theorem 11 need not be true.

Example
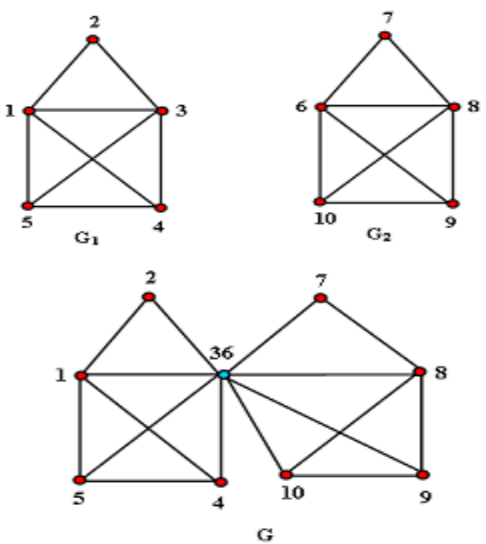

Figure 5. $\mathrm{G}$ is a dss graph, $\mathrm{d}(\mathrm{G})=\mathrm{d}\left(\mathrm{G}_{1}\right)=\mathrm{d}\left(\mathrm{G}_{2}\right)=3, \mathrm{~d}\left(\mathrm{G}_{1}-\{3\}\right)=$ $\mathrm{d}\left(\mathrm{G}_{2}-\{6\}\right)=2$, that is $\mathrm{d}\left(\mathrm{G}_{1}\right) \neq \mathrm{d}\left(\mathrm{G}_{1}-\{3\}\right)$ and $\mathrm{d}\left(\mathrm{G}_{2}\right) \neq \mathrm{d}\left(\mathrm{G}_{2}-\right.$ $\{6\})$.

\section{Theorem 12}

If $\mathrm{G}_{1}$ and $\mathrm{G}_{2}$ are dss graphs such that $\mathrm{d}\left(\mathrm{G}_{1}\right)=\mathrm{d}\left(\mathrm{G}_{2}\right)=2$, $\mathrm{d}\left(\mathrm{G}_{1}\right)=\mathrm{d}\left(\mathrm{G}_{1}-\{\mathrm{u}\}\right), \mathrm{d}\left(\mathrm{G}_{2}\right)=\mathrm{d}\left(\mathrm{G}_{2}-\{\mathrm{v}\}\right)$, for some $\mathrm{u} \in \mathrm{V}_{1}, \mathrm{v} \in \mathrm{V}_{2}$, then the graph $\mathrm{G}$ obtained by merging $\mathrm{u}$ and $\mathrm{v}$ is also dss.

Proof

By Theorem 10, we know that $d(G)=2$. For any graph $G$, 
$d(G) \geq 2$, which implies $d\left(G_{\text {sd }} x y\right) \geq 2$, for all $x y \in E(G)$. For any $\mathrm{e} \in \mathrm{E}(\mathrm{G})$, either $\mathrm{e} \in \mathrm{E}\left(\mathrm{G}_{1}\right)$ or $\mathrm{e} \in \mathrm{E}\left(\mathrm{G}_{2}\right)$. Assume that $e \in E\left(G_{1}\right)$. If possible assume that $d\left(G_{s d} x y\right)$ $=3$, $x y \in E\left(G_{1}\right)$. By $R_{3}$, there is a domatic partition $\mathrm{d}(\mathrm{G})=$ $\left|\left\{\mathrm{V}_{1}\right\},\left\{\mathrm{V}_{2}\right\}\right|, \mathrm{x} \in \mathrm{V}_{1}, \mathrm{y} \in \mathrm{V}_{2}$ such that

i. $\quad \mathrm{x}$ is $2-$ dominated with respect to $\mathrm{V}_{1}$.

ii. $\quad V_{2}=V_{12} \cup V_{22}$, where

a. $\mathrm{y} \in \mathrm{V}_{12}$, $\mathrm{y}$ is 2 - dominated with respect to $\mathrm{V}_{12}$.

b. $\mathrm{V}_{22}$ does not dominate atleast one of $\mathrm{x}$ or $\mathrm{y}$, that is $\mathrm{V}_{22}$ is a dominating set for $\mathrm{G}-\{\mathrm{x}\}-\{\mathrm{y}\} .\left\{\mathrm{V}_{1}, \mathrm{~V}_{12}, \mathrm{~V}_{22}\right.$ $\cup\{\mathrm{w}\}$ is a domatic partition for $\mathrm{G}_{1 \text { sd }} \mathrm{xy}$ such that $\mathrm{x}$ $\in \mathrm{V}_{1}, \mathrm{y} \in \mathrm{V}_{12}$, which implies $\mathrm{d}\left(\mathrm{G}_{1 \text { sd }} \mathrm{xy}\right)=3$, a contradiction as $G_{1}$ is dss. This implies $d\left(G_{\text {sd }} x y\right) \neq 3$, Example that is $d\left(G_{s d} x y\right)=2$. Hence $G$ is dss.

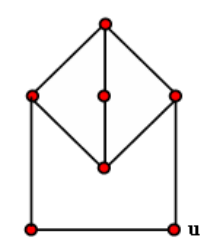

$\mathbf{G}_{1}$

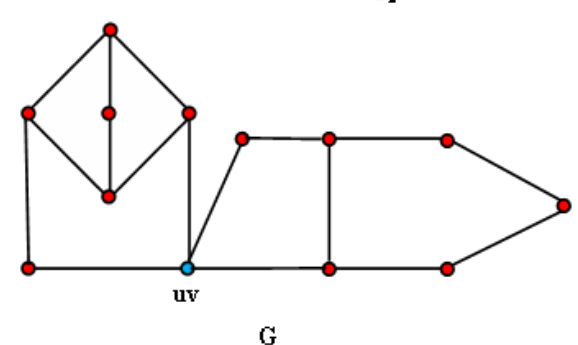

G

Figure 6. $d\left(G_{1}\right)=d\left(G_{1 s d} x y\right)=2, x y \in E\left(G_{1}\right)$ and $d\left(G_{2}\right)=d\left(G_{2 \text { sd }} x y\right)$ $=2$, $x y \in E\left(G_{2}\right)$. Here $d(G)=d\left(G_{s d} a b\right)=2$, for all $a b \in E(G)$.

\section{Conclusion}

Using $R_{1}$, for the graph $G, G_{1}, G_{2}$ in the above notations of Theorem 11 and 12 , we conclude that, if $\mathrm{G}_{1}$ and $\mathrm{G}_{2}$ are dss, then $\mathrm{G}$ is also dss.

Vestergaard, P. D and Zelinka. B. [2], have proved the following results.

Let $\mathrm{H}$ be the graph obtained from two disjoint graphs $\mathrm{H}_{1}$, $\mathrm{H}_{2}$ by joining a vertex $\mathrm{a}_{1}$ of $\mathrm{H}_{1}$ with a vertex $\mathrm{a}_{2}$ of $\mathrm{H}_{2}$ by a bridge $b . \mathrm{By}{ }^{\prime}$ we denote the graph obtained from $\mathrm{H}_{1}$ by deleting $\mathrm{a}_{1}$, by $\mathrm{H}_{2}{ }^{\prime}$ the graph obtained from $\mathrm{H}_{2}$ by deleting $\mathrm{a}_{2}$.

$\mathrm{R}_{5}$. For the domatic numbers of $\mathrm{H}, \mathrm{H}_{1}, \mathrm{H}_{2}$ the following inequalities hold:

$\min \left\{\mathrm{d}\left(\mathrm{H}_{1}\right), \mathrm{d}\left(\mathrm{H}_{2}\right)\right\} \leq \mathrm{d}(\mathrm{H}) \leq 1+\min \left\{\mathrm{d}\left(\mathrm{H}_{1}\right), \mathrm{d}\right.$ $\left.\left(\mathrm{H}_{2}\right)\right\}$.

$\mathrm{R}_{6}$. For the graphs $\mathrm{H}, \mathrm{H}_{1}, \mathrm{H}_{2}$ in the above notations the equality $\mathrm{d}(\mathrm{H})=1+\min \left\{\mathrm{d}\left(\mathrm{H}_{1}\right), \mathrm{d}\left(\mathrm{H}_{2}\right)\right\}$ holds if and only if the following condition is fulfilled: For each $\mathrm{i} \in\{1,2\}$ such that $\mathrm{d}\left(\mathrm{H}_{\mathrm{i}}\right)=\min \left\{\mathrm{d}\left(\mathrm{H}_{1}\right), \mathrm{d}\left(\mathrm{H}_{2}\right)\right\}$ there exists a partition $\left\{\mathrm{D}_{1}{ }^{\mathrm{i}}, \mathrm{D}_{2}{ }^{\mathrm{i}}, \ldots, \mathrm{D}_{\mathrm{d}+1}{ }^{\mathrm{i}}\right\}$ ( where $\left.\mathrm{d}=\mathrm{d}\left(\mathrm{H}_{\mathrm{i}}\right)\right)$ of the vertex set of $\mathrm{H}_{\mathrm{i}}$ such that $\mathrm{D}_{1}{ }^{\mathrm{i}}, \ldots, \mathrm{D}_{\mathrm{d}}{ }^{\mathrm{i}}$ are dominating sets in $\mathrm{H}_{\mathrm{i}}$ and $\mathrm{D}_{\mathrm{d}+1}{ }^{\mathrm{i}}$ is a dominating set in $\mathrm{H}_{\mathrm{i}}{ }^{\prime}$, but not in $\mathrm{H}_{\mathrm{i}}$.

$N$ : Let $G_{1}$ and $G_{2}$ be two graphs such that $d\left(G_{1}\right)=d\left(G_{2}\right)$

=3. Let $u \in V\left(G_{1}\right), v \in V\left(G_{2}\right)$. Let $G$ be the graph obtained by joining $\mathrm{u}$ and $\mathrm{v}$ with a bridge.

Theorem 13

Let $G, G_{1}, G_{2}$ be the graphs satisfying the above notation $\mathrm{N}$. Then $\mathrm{d}(\mathrm{G})=3$ and $\mathrm{G}$ is dss if and only if there exist no partition $D_{1}{ }^{i}, D_{2}{ }^{i}, D_{3}{ }^{i}, D_{4}{ }^{i}$ for the vertex set of $G_{i}$ such that $\mathrm{D}_{1}{ }^{\mathrm{i}}, \mathrm{D}_{2}{ }^{\mathrm{i}}, \mathrm{D}_{3}{ }^{\mathrm{i}}$ are dominating sets for $\mathrm{G}_{\mathrm{i}}, \mathrm{D}_{4}{ }^{\mathrm{i}}$ are dominating sets for $G_{i}^{\prime}$ but not for $G_{i}$.

Proof

By $R_{5}$ and $R_{6} d(G) \leq 3$. Since $d\left(G_{1}\right)=d\left(G_{1 \text { sd }} x y\right)=d$ $\left(\mathrm{G}_{2}\right)=\mathrm{d}\left(\mathrm{G}_{2 \text { sd }} \mathrm{xy}\right)=3$, let $\mathrm{d}\left(\mathrm{G}_{1}\right)=\left|\left\{\mathrm{U}_{1}\right\},\left\{\mathrm{U}_{2}\right\},\left\{\mathrm{U}_{3}\right\}\right|, \mathrm{d}\left(\mathrm{G}_{1}\right.$ sd $\mathrm{xy})=\left|\left\{\mathrm{X}_{1}\right\},\left\{\mathrm{X}_{2}\right\},\left\{\mathrm{X}_{3}\right\}\right|, \mathrm{d}\left(\mathrm{G}_{2}\right)=\mid\left\{\mathrm{V}_{1}\right\},\left\{\mathrm{V}_{2}\right\}$, $\left\{\mathrm{V}_{3}\right\}\left|, \mathrm{d}\left(\mathrm{G}_{2 \text { sd }} \mathrm{xy}\right)=\right|\left\{\mathrm{Y}_{1}\right\},\left\{\mathrm{Y}_{2}\right\},\left\{\mathrm{Y}_{3}\right\}|.| \mathrm{U}_{\mathrm{i}} \cup \mathrm{V}_{\mathrm{i}} \mid, \mathrm{i}=1$, 2,3 is a domatic partition for $\mathrm{G}$, which implies $\mathrm{d}(\mathrm{G})=3$.

Let $e \in E(G)$, either $e \in E\left(G_{1}\right)$ or $e \in E\left(G_{2}\right)$ or $e=u v$.

i. If $e=x y \in E\left(G_{1}\right)$, then $\left|X_{i} \cup V_{i}\right|$ is a domatic partition for $\mathrm{G}, \mathrm{i}=1,2,3$.

ii. If $\mathrm{e}=\mathrm{xy} \in \mathrm{E}\left(\mathrm{G}_{2}\right)$, then $\left|\mathrm{Y}_{\mathrm{i}} \cup \mathrm{U}_{\mathrm{i}}\right|$ is a domatic partition for $\mathrm{G}, \mathrm{i}=1,2,3$.

iii. If e $=u v$, let $u s$ assume that $u \in U_{1}, v \in V_{1}, U_{1} \cup V_{2}$ is a dominating set for $\mathrm{G}_{\mathrm{sd}} \mathrm{uv}$, since $\mathrm{v}$ is 2 -dominated. $\mathrm{U}_{2} \cup \mathrm{V}_{1}$ is a dominating set for $\mathrm{G}_{\mathrm{sd}} \mathrm{uv}$, since $\mathrm{u}$ is $2-$ dominated. $\mathrm{U}_{3} \cup \mathrm{V}_{3} \cup\{\mathrm{w}\}$ is a dominating set for $\mathrm{G}_{\mathrm{sd}} \mathrm{uv}$, that is $\mathrm{d}\left(\mathrm{G}_{\mathrm{sd}} \mathrm{uv}\right)=\mid\left\{\mathrm{U}_{1} \cup \mathrm{V}_{2}\right\},\left\{\mathrm{U}_{2} \cup \mathrm{V}_{1}\right\}$, $\left\{\mathrm{U}_{3} \cup \mathrm{V}_{3} \cup\{\mathrm{w}\}\right\} \mid$ such that $\mathrm{u} \in \mathrm{U}_{1} \cup \mathrm{V}_{2}, \mathrm{v} \in \mathrm{U}_{2} \cup$ $\mathrm{V}_{1}$.

From i, ii and iii we conclude that $d(G) \geq 3$. Since $P_{3}$ : xwy is a subgraph of $G$, by $R_{1}$, we know that $d\left(G_{\text {sd }} x y\right) \leq 3$, which implies $d\left(\mathrm{G}_{\mathrm{sd}} \mathrm{xy}\right)=3$.

We conclude that $d(G)=d\left(G_{s d}\right.$ ab $)=3$, for all $a b \in E$ ( $\mathrm{G}$ ).

Assume that, $\mathrm{G}$ is a dss graph such that $\mathrm{d}(\mathrm{G})=3$. By our assumption $\mathrm{d}\left(\mathrm{G}_{1}\right)=\mathrm{d}\left(\mathrm{G}_{2}\right)=3, \mathrm{G}_{1}$ and $\mathrm{G}_{2}$ are dss graphs. Let $\mathrm{G}_{1}{ }^{\prime}=\mathrm{G}_{1}-\{\mathrm{u}\}, \mathrm{G}_{2}{ }^{\prime}=\mathrm{G}_{2}-\{\mathrm{v}\}$. If there is a partition $\mathrm{d}$ $\left(\mathrm{G}_{\mathrm{i}}\right)=\left|\left\{\mathrm{D}_{1}{ }^{\mathrm{i}}\right\},\left\{\mathrm{D}_{2}{ }^{\mathrm{i}}\right\},\left\{\mathrm{D}_{3}{ }^{\mathrm{i}}\right\},\left\{\mathrm{D}_{4}{ }^{\mathrm{i}}\right\}\right|$, so that $\mathrm{D}_{1}{ }^{\mathrm{i}}, \mathrm{D}_{2}{ }^{\mathrm{i}}, \mathrm{D}_{3}{ }^{\mathrm{i}}$ are dominating sets for $\mathrm{G}_{\mathrm{i}}, \mathrm{D}_{4}{ }^{\mathrm{i}}$ are dominating sets for $\mathrm{G}_{\mathrm{i}}{ }^{\prime}$ but not for $G_{i}$, then by $R_{6} d(G)=4$, a contradiction to our assumption $d(G)=3$. This implies $G, G_{1}, G_{2}$ are graphs which satisfy the condition of the theorem.

Example

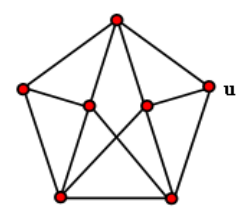

$\mathbf{G}_{1}$

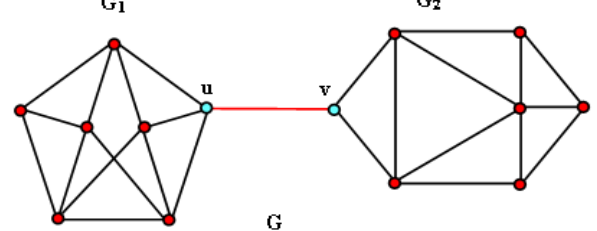

G

Figure 7. $d\left(G_{1}\right)=d\left(G_{1 s d} x y\right)=3, x y \in E\left(G_{1}\right)$ and $d\left(G_{2}\right)=d\left(G_{2 s d} x y\right)$ $=3$, $x y \in E\left(G_{2}\right)$. Here $d(G)=d\left(G_{s d} a b\right)=3$, for all $a b \in V(G)$.

Theorem 14

With the notation for the domatic numbers of $G, G_{1}, G_{2}, d$ 
$(\mathrm{G})=2$ and $\mathrm{G}$ is dss.

Proof

For any $\mathrm{e} \in \mathrm{E}(\mathrm{G})$, either $\mathrm{e} \in \mathrm{E}\left(\mathrm{G}_{1}\right)$ or $\mathrm{e} \in \mathrm{E}\left(\mathrm{G}_{2}\right)$ or e $=u v$. If possible assume that $\mathrm{d}\left(\mathrm{G}_{\mathrm{sd}} \mathrm{xy}\right)=3, \mathrm{x} \perp \mathrm{y}$.

i. $\quad \mathrm{e}=\mathrm{xy} \in \mathrm{E}\left(\mathrm{G}_{1}\right)$.

Proof is similar to the proof of Theorem 12. As in Theorem 12, we get a contradiction, since $\left\{V_{1}, V_{12}, V_{22} \cup\right.$ $\{w\}\}$ is a domatic partition for $\mathrm{G}_{1 \mathrm{sd}} \mathrm{xy}$.

ii. $\quad \mathrm{e}=\mathrm{xy} \in \mathrm{E}\left(\mathrm{G}_{2}\right)$.

Contradiction as in (i).

iii. $\quad \mathrm{e}=u v$

Let $d(G)=\left|\left\{V_{1}\right\},\left\{V_{2}\right\}\right|$, that satisfies the conditions of $\mathrm{R}_{3}$. Let $\mathrm{V}_{1}=\mathrm{X}_{1} \cup \mathrm{X}_{2}$, where $\mathrm{V}\left(\mathrm{X}_{1}\right) \subseteq \mathrm{V}\left(\mathrm{G}_{1}\right), \mathrm{V}\left(\mathrm{X}_{2}\right) \subseteq$ $\mathrm{V}\left(\mathrm{G}_{2}\right)$. Let $\mathrm{V}_{12}=\mathrm{Y}_{1} \cup \mathrm{Y}_{2}$, where $\mathrm{V}\left(\mathrm{Y}_{1}\right) \subseteq \mathrm{V}\left(\mathrm{G}_{1}\right), \mathrm{V}\left(\mathrm{Y}_{2}\right)$ $\subseteq \mathrm{V}\left(\mathrm{G}_{2}\right) . \mathrm{V}_{22}=\mathrm{Z}_{1} \cup \mathrm{Z}_{2}$, where $\mathrm{V}\left(\mathrm{Z}_{1}\right) \subseteq \mathrm{V}\left(\mathrm{G}_{1}\right), \mathrm{V}\left(\mathrm{Z}_{2}\right)$ $\subseteq \mathrm{V}\left(\mathrm{G}_{2}\right)$. Let $\mathrm{Z}=\left\{\mathrm{X}_{1}, \mathrm{Y}_{1}, \mathrm{Z}_{1}\right\} . \mathrm{Z}$ is a domatic partition for $\mathrm{G}_{1}$ such that $X_{1}, Y_{1}$ are dominating sets for $G_{1}, Z_{1}$ dominates $\mathrm{G}_{1}-\{\mathrm{u}\}, \mathrm{d}(\mathrm{G})=1+\min \left\{\mathrm{d}\left(\mathrm{G}_{1}\right), \mathrm{d}\left(\mathrm{G}_{2}\right)\right\}=1+2=3$, a contradiction as $\mathrm{d}(\mathrm{G})=2$.

From i, ii and iii $d\left(G_{s d} u v\right) \neq 3$, that is $d\left(G_{s d} u v\right)=2$. Hence $G$ is dss.

Example

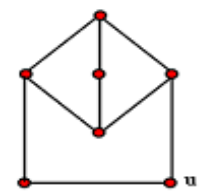

$\mathbf{G}_{1}$

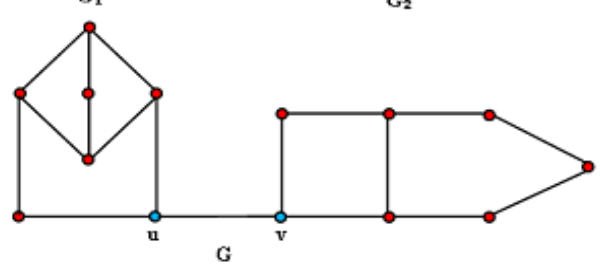

Figure 8. $d\left(G_{1}\right)=d\left(G_{1 s d} x y\right)=2, x y \in E\left(G_{1}\right)$ and $d\left(G_{2}\right)=d\left(G_{2 \text { sd }} x y\right)$ $=2, x y \in E\left(G_{2}\right)$. Here $d(G)=d\left(G_{s d} a b\right)=2$, for all $a b \in E(G)$.

\section{Conclusion}

For the graph $\mathrm{G}, \mathrm{G}_{1}, \mathrm{G}_{2}$ in the above notations of theorem 13 and 14 , we conclude that, if $G_{1}$ and $G_{2}$ are dss, then $G$ is also dss.

\section{Conclusion and Future Work}

We have used only two graph operations for generating new dss from existing ones. One can generate new dss graphs by applying other graph operations like union, intersection, ring sum etc. Just like the operation to build the larger graphs from smaller ones, one can also do the opposite, decompose a large graph, that is dss graph to smaller graphs that are dss.

\section{REFERENCES}

[1] D. B. West. Introduction to graph theory, second ed., Prentice - Hall, New Jersey 2007.

[2] P. D. Vestergaard and B. Zelinka.. Cut - Vertices and Domination In Graphs, Mathematica Bohemica, Vol. 120, No. 2, pp: $135-143,1995$.

[3] T. W. Haynes, S. T. Hedetniemi, Fundamentals of Domination in Graphs, Marcel Dekker, New York, 1998.

[4] T. W. Haynes, S. T. Hedetniemi, and P. J. Slater, Domination in Graphs - Advanced Topics, Marcel Dekker, New York, 1998.

[5] M. Yamuna and K. Karthika. Domination Stable Graphs, LAP Lambert Academic Publishing, Germany, 2012.

[6] M. Yamuna and K. Karthika. Domatic Subdivision Stable Graphs, Global Journal of Pure and Applied Mathematics, Vol. 9, No. 2, pp: 137 - 142, 2013. 